\title{
Salmonella typhimurium flhE, a conserved flagellar regulon gene required for swarming
}

\author{
Graham P. Stafford and Colin Hughes \\ Cambridge University Department of Pathology, Tennis Court Road, Cambridge CB2 1OP, UK
}

Correspondence

Graham P. Stafford

gps25@cam.ac.uk

The Salmonella typhimurium gene flhE is located at the end of a large flagellar locus in at least 10 peritrichously flagellated Gram-negative bacterial genera, but it shares no significant similarity with other genes. This study shows that $f / h E$ is transcribed as part of an fIhBAE flagellar operon, under the control of the flagellar master regulator $\mathrm{FlhD}_{2} \mathrm{C}_{2}$. Deletion of the chromosomal flhE gene did not affect swimming motility, but it abolished swarming motility across solid agar. Swarming was restored to the $\triangle f / h E$ mutant by the 130 aa putative envelope protein FlhE, but not by a truncated version lacking the $\mathrm{N}$-terminal signal peptidase I recognition sequence. The $\Delta f / h E$ mutant was indistinguishable from the wild-type parent in number and distribution of flagella, secretion of flagellin subunits, and flagellar gene expression, and there were no obvious differences in cellsurface LPS and extracellular polysaccharide. The $\triangle f / h E$ mutant was able to swarm when non-ionic surfactant was included in agar medium, and it showed differences to the wild-type in binding calcofluor and Congo red dyes, and in biofilm production. The data show that the flhE gene is part of the flagella regulon but that it has no role in flagella biogenesis. It appears, nevertheless, to act at the cell envelope to influence flagella-dependent swarming.

Received 18 September 2006

Revised 9 November 2006

Accepted 10 November 2006
Motility genes are clustered within three loci around the chromosome of Sal. typhimurium and related bacteria (Macnab, 1996), and their approximate function has, in virtually all cases, been established. In this paper, we reexamine the gene flhE. This gene was given a flagellar nomenclature due to its location at the end of a large flagellar and chemotaxis gene locus, but an early report has indicated that it is not involved in motility (Minamino et al., 1994).

\section{METHODS}

motor and chemotaxis apparatus (Chadsey et al. 1998. Karlinsey et al., 2000). Assembly of the flagella is strictly ordered, and coupled to this expression programme. The FlhD $\mathrm{C}_{2}$ activator also controls non-flagellar genes in an extended motility regulon (Stafford et al., 2005; Soutourina \& Bertin, 2003). Multicellular swarming migration over solid surfaces (Allison \& Hughes, 1991) requires increased flagella production via upregulation of flhDC (Fraser \& Hughes, 1999; Dufour et al., 1998; Hay et al., 1997; Givskov et al., 1995), and other cell surface components that facilitate assembly of swarm cell rafts (Hay et al., 1999; Allison et al., 1994), and surface lubrication by LPS (Toguchi et al., 2000; Belas et al., 1995), exopolysaccharide (EPS) (Gygi et al., 1995) and secreted surfactant (Toguchi et al., 2000; Gygi et al., 1995; Lai et al., 2005).

Abbreviations: EPS, exopolysaccharide; $\mathrm{EtBr}$, ethidium bromide.
Bacterial strains and plasmids. Bacterial strains were grown at $37^{\circ} \mathrm{C}$ in $\mathrm{LB}$, unless stated otherwise. Swarm cells were isolated after $6 \mathrm{~h}$ incubation on swarm agar $(0.6 \%$ Bacto agar plus $0.5 \%$ glucose; Wang et al., 2004). Wild-type Sal. typhimurium SJW1103 (Yamaguchi et al., 1984) is motile, and the isogenic flhDC mutant SJW1368 is non-motile (Ohnishi et al., 1994). Deletion of flhE was achieved by the method of Datsenko \& Wanner (2000) to create the $\triangle$ flhE strain, using primers $\triangle$ flhEFor (TCCGATAACCGTCATATCCGCATGCACGGCGACCATTGGAGGAAAATAATGGTGTAGGCTGGAGCTGCTTC) and $\Delta$ flhERev (TCCGGCAACCTACCTCACTTTATAAAACAGCGTTTCTATTTATTCAAATTCCGGGGATCCGTCGACC), and the pKD4 $\left(\mathrm{Km}^{\mathrm{R}}\right)$ plasmid as a template (Datsenko \& Wanner, 2000). Deletion of the flhE gene was verified by PCR. The entire flhE gene was amplified by PCR using primers FlhEfor (TGGAGGAAACATATGCGTAAATGGCTGGCGTTG) and FlheRev (AACCCTCGAGGCGGTAGTTCACAATCACC), and cloned (XbaI-HindIII) 5' of the arabinose-inducible promoter of expression vector $\mathrm{pBAD} 18$, to create $\mathrm{pBAD} 18$-FlhE. A derivative gene encoding N-terminally truncated FlhE $\Delta \mathrm{N}$ (lacking aa 1-16) 
was cloned into pBAD18 after PCR using primers FlhE-T (AATTCTAGAAATAATTTTGTTAACTTTAAGAAGATATACCATGGGCGAAGGCGCGTGGCAG) and FlhERev to make pBAD18-FlhE $\Delta$ N.

Fluorescence microscopy of cells. Cells scraped from swarm plates were resuspended in saline (to an $\mathrm{OD}_{600}$ of 0.05 ), and fixed onto glass slides using $4 \%$ paraformaldehyde (in $20 \mathrm{mM}$ PIPES, $\mathrm{pH}$ 7.4) before blocking with PBS $\left(50 \mathrm{mM} \mathrm{NaPO} / \mathrm{Na}_{2} \mathrm{PO}_{4}, \mathrm{pH} 7.4\right.$, $150 \mathrm{mM} \mathrm{NaCl}$ ) plus $3 \%(\mathrm{w} / \mathrm{v}) \mathrm{BSA}$ for $1 \mathrm{~h}$ at $25^{\circ} \mathrm{C}$. Primary antiflagellin antibody $(1 / 1000, v / v$, in PBS) was added for $2 \mathrm{~h}$ before washing $(2 \times 10 \mathrm{~min}$, PBS $)$, incubation with AlexaFluor-488/594conjugated anti-rabbit secondary antibody $(1 / 1000, \mathrm{v} / \mathrm{v}$, in PBS; Molecular Probes) $\left(2 \mathrm{~h}, 25^{\circ} \mathrm{C}\right)$, and further washing $(3 \times 10 \mathrm{~min}$, PBS). Cell membranes were stained for $10 \mathrm{~min}$ with SynaptoRed (in the dark), and coverslips were mounted using ProLong Anti-fade reagent (Molecular Probes), and visualized using a fluorescence microscope (Leica DM IRBE). Images were captured by a CCD digital camera (Hamamatsu) and processed using OpenLab software (Improvision).

Cell fractionation. Harvested swarm cells were resuspended in $\mathrm{PBS}$, and diluted to an $\mathrm{OD}_{600}$ of 1.0. Total extracellular FliC protein was prepared by shearing ( 5 min vortex) of harvested cells, and TCA precipitation $(10 \%, \mathrm{v} / \mathrm{v}$, final concentration) of cell-free supernatant at $4{ }^{\circ} \mathrm{C}$ for $1 \mathrm{~h}$. Extracellular protein was centrifuged for $1 \mathrm{~h}$ at $300000 \mathrm{~g}$ to separate filament (pellet) from monomeric flagellin (soluble fraction, precipitated with $10 \% \mathrm{TCA}, 4{ }^{\circ} \mathrm{C}, 1 \mathrm{~h}$ ). Cells were separated into cytosolic and membrane fractions according to Auvray et al. (2001).

LPS and EPS extraction. Crude LPS was prepared from swarm cells (number of cells equivalent to $1 \mathrm{ml}$ culture at an $\mathrm{OD}_{600}$ of 1 ), according to Hitchcock \& Brown (1983). LPS was also extracted by a hot-phenol method for analysis by urea (high molecular mass) and deoxycholate-SDS (low molecular mass) PAGE, and visualized using silver staining (Guard-Petter et al., 1995). EPS was isolated and visualized according to Gygi et al. (1995).

Biofilm assay. Overnight cultures grown in biofilm LB (10 g tryptone $1^{-1}, 5 \mathrm{~g}$ yeast extract $1^{-1}$ ) were inoculated at a 1 in 10 dilution into 96-well PVC microtitre plate wells (Falcon) containing fresh biofilm LB plus $0.5-2 \%$ glucose, and incubated overnight at $30{ }^{\circ} \mathrm{C}$. Biofilm was washed twice with distilled water, air-dried for $30 \mathrm{~min}$, and stained for 15 min with $1 \%$ crystal violet before washing with water and air drying. Biofilm was quantified as absorbance at $550 \mathrm{~nm}$, following extraction with $95 \%$ ethanol (Mireles et al., 2001).

In vivo assay of transcription. Transcription was assessed as cell $\beta$-galactosidase activity (Miller, 1972) of gene fusions created by EcoRI/BamHI cloning of flhB (using primers FlhBPromEco, GAATTCACACGAGACTTTCTTTATC; and FlhBPromBam, GGATCCGCAAACCCTGGATAG) and fliC (primers FliCpromEco, GAATTCTTTTGCAAAAATAATGC; and FliCpromBam, GGATCCTCAATTACAACTTGATG) promoter fragments into the lac $Z$ fusion vector pGPS123 (Stafford et al., 2005), which is identical to pRS551 except that $\mathrm{Km}^{\mathrm{R}}$ is replaced by $\mathrm{Gm}^{\mathrm{R}}$ (Simons et al., 1987). For RTPCR, RNA was extracted from swarm cells using hot acidic phenol. After removal of contaminating DNA by using Rq1 DNase (Promega), cDNA specific for the $f l h B$ and $f l h E$ genes was synthesized using Mu-MLV reverse transcriptase (Promega), and primers flhBRevRT (TTCGGCGTGGCGATATAATG) and flhERevRT (ATTGCTCCGCACTTTTAACG), resulting in cDNA originating within $f l h B$ and $f l h E$, respectively. In the final step, primers flhBRevRT/flhBForRT (internal to flhB, ACCGCTCATCGCGGGCGTGG) and flhERevRT/flhEForRT (flhE internal, TGGCGTTGTTGCTCTTTCC) were used to amplify internal fragments of flhB and flhE. To assess transcripts spanning the flhBA and flh $A E$ intergenic regions, primer pairs flhBForRT/flhARevRT (TCGCGAAGTTACCGCCGACCAGG) and flhAForRT (TCCGATAACCGTCATATCC)/flhERTRev were used. All PCR reactions used Taq polymerase, and products were analysed on $1.5 \%$ agarose ethidium bromide (EtBr) gels.

\section{RESULTS AND DISCUSSION}

\section{The flhE gene in the flagellar loci of peritrichously flagellated bacteria}

The flhE gene in Sal. typhimurium is located immediately downstream of the flhBA genes, and the flhA stop codon overlaps the flhE start codon (Fig. 1). Nevertheless, a transposon insertion in $f l h E$ has indicated that the gene is not essential for swimming motility, casting doubt on its flagellar gene nomenclature (Minamino et al., 1994). Our renewed interest in $f l h E$ was prompted by its presence in the flagellar gene loci of over 10 genera of peritrichous Gramnegative bacteria (Fig. 1). In the Enterobacteriaceae Esc. coli, Serratia marcescens, Erwinia carotovora, Yersinia pestis, Citrobacter rodentium and Shigella flexneri, flhE is located as in Sal. typhimurium, i.e. immediately distal to $f l h B A$ encoding the integral membrane flagellar export proteins FlhB and FlhA (except in Shigella, which contains no flhA gene). The flhE genes from the human pathogens Esc. coli, $Y$. pestis, Cit. rodentium and Shi. flexneri are similarly located at the end of motility gene locus, with non-flagellar genes downstream, and they are apparently transcribed independently from flhE. In Erwinia and Serratia, the $f l h B A(E)$ genes lie immediately adjacent to the chemotaxis genes cheBYZ, and within a still larger flagellar gene cluster containing the divergently transcribed flgAMN and flgBCDEFGHIJKL genes. In the free-living soil microbes Azotobacter vinelandii and Chromohalobacter salexigens, flhE is located downstream of the flhFG genes thought to be involved in flagellar assembly and gene regulation (McCarter 2001), while in Ralstonia metallidurans, flhE is separated from flh $G$ by the $f l i A$ gene that encodes the flagella-specific sigma factor $\sigma^{28}$. The flhE gene is thus always linked to flagella genes, and has not been located separately from flagellar gene loci. The sequence identity between the deduced amino acid sequence of Sal. typhimurium FlhE, and those of other Enterobacteriaceae, ranges from 37 to $83 \%$, while it is lower (28-38\%) for A. vinelandii, R. metallidurans and Chr. salexigens. All the flhE genes are $400 \pm 25$ bp and encode proteins of approximately $14 \mathrm{kDa}$, with a predicted $\mathrm{N}$ terminal signal peptidase I leader sequence, and a predicted periplasmic or outer membrane location; the FlhE sequences of the 10 genera in Fig. 1 contain between 7 and 13 apparently randomly distributed proline residues. BLAST searches revealed no significant similarity of FlhE to any class of proteins.

\section{flhE is transcribed in an fIhBAE operon activated by FIhD $_{2} \mathrm{C}_{2}$}

The flhBA operon is transcribed from a class II (early) flagellar promoter upstream of $\mathrm{flh} B$, and is therefore 


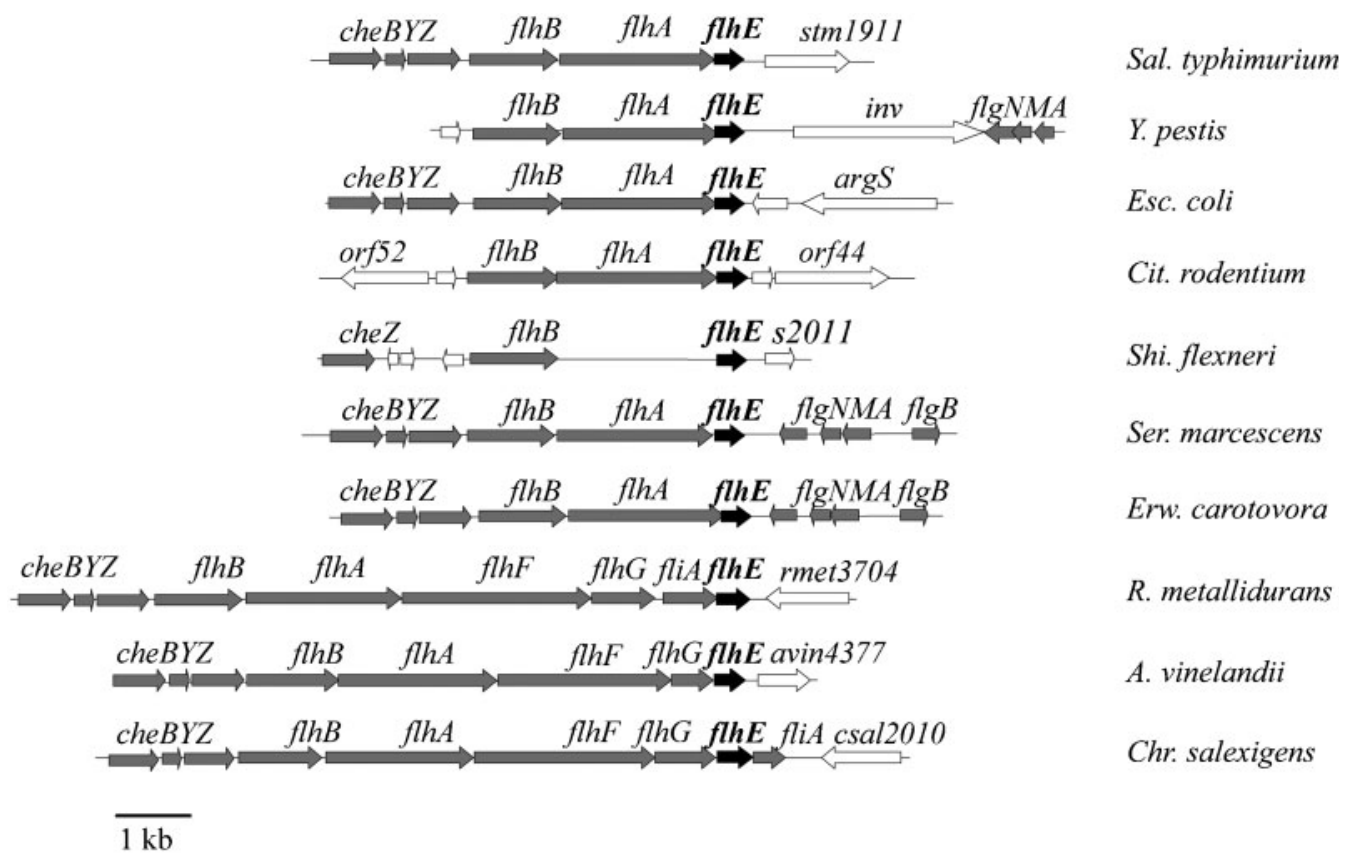

Fig. 1. Location of $f / h E$ gene in peritrichous flagellated eubacteria. The flhE gene is shown in black, flagellar genes are in grey and non-flagellar genes are in white. Using the predicted amino acid sequence of the Sal. typhimurium LT2 flhE gene (AAL20828.1) with the BLASTP algorithm (Altschul et al., 1997) and the colibase website (Chaudhuri et al., 2004), flhE was identified in Y. pestis (GenBank accession no. NP_669822), Esc. coli (AAC74948), Cit. rodentium (colibase GL096266), Shi. flexneri (AAN43476), Ser. marcescens (colibase GL076148), Erw. carotovora (colibase CAG74604), R. metallidurans (YP_585844), A. vinelandii (ZP_00417385) and Chr. salexigens (ABE59363).

activated by the flagellar master regulator $\mathrm{FlhD}_{2} \mathrm{C}_{2}$ (Fig. 2). To assess whether expression of flhE is flagellar-like, we purified RNA from wild-type and $f l h D C^{-}$strains, and performed RT-PCR using primers targeted within the flhE gene and the class II $f l h B$ gene. The results (Fig. 2) show that transcription of flhE was dependent on $\mathrm{FlhD}_{2} \mathrm{C}_{2}$, i.e. it mirrored that of $f l h B$. We assessed whether flhE was transcribed as part of a contiguous polycistronic messenger RNA molecule by measuring transcription across the flhBA and $f l h A E$ intergenic regions in the wild-type and $f l h D C^{-}$ strains. Fig. 2 shows that flhE is transcribed as part of a polycistronic messenger RNA in an flhDC-dependent manner, and it indicates that there is no post-transcriptional processing of the messenger RNA in vivo. These expression data establish flhE as part of the $\mathrm{FlhD}_{2} \mathrm{C}_{2}$ regulon, and indeed as part of an flhBAE operon. Together with the conserved location of flhE in the flagellar loci of peritrichously flagellated bacteria, this gives renewed validity to its designation as a flagellar gene. We investigated the possible function of flhE in motility.

\section{Loss of flhE attenuates swarming but not swimming}

We set out to re-examine a possible role for flhE in motility by constructing an flhE deletion strain using the method of Datsenko \& Wanner (2000). We confirmed the report by
Minamino et al. (1994) that the swimming phenotype of such a mutant is at most only marginally reduced from the wild-type (Fig. 3). However, in common with several
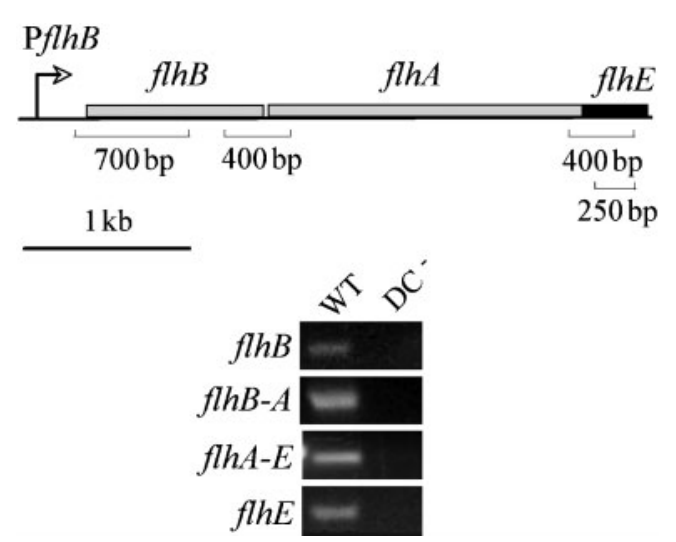

Fig. 2. Transcription of $f / h E$ as part of the Sal. typhimurium fIhBAE operon. RT-PCR reactions were performed on RNA extracted from swarm cells of wild-type (WT) and $f / h D C^{-}$ strains, and products (sizes and corresponding locations are indicated in the top panel) within the flhB and flhE coding sequences, and spanning junctions between flhB-A and flhA-E were visualized by UV illumination of $1.5 \%$ agarose $\mathrm{EtBr}$ gels. 


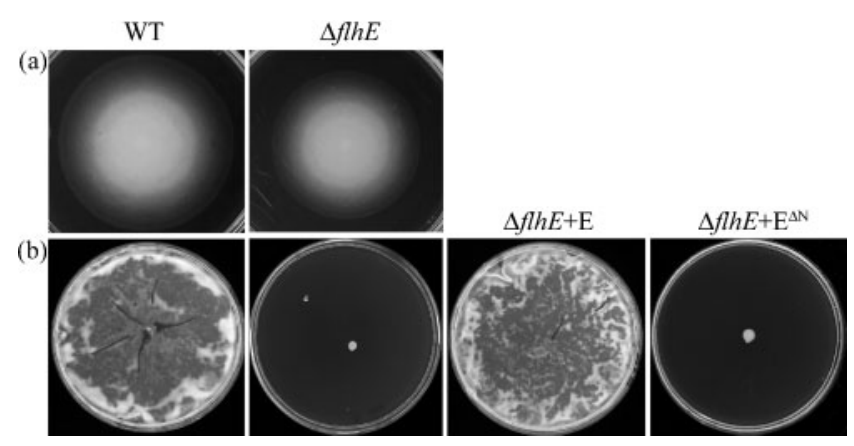

Fig. 3. Effect of flhE deletion on Sal. typhimurium motility. Wild-type (WT), the $\triangle f / h E$ mutant and the $\triangle f / h E$ mutant complemented with pBAD18-FlhE (E) and FlhE $^{\Delta N}$ pBAD18-FlhE ${ }^{\Delta N}$ $\left(E^{\Delta N}\right)$ were incubated on media for (a) swimming (0.35\% agar, $6 \mathrm{~h}$ ) and (b) swarming (0.6\% agar $+0.5 \%$ glucose, overnight).

Gram-negative species, Salmonella is also capable of swarming motility, which is a form of flagella-dependent mass migration that is assayed as movement across the surface of denser $0.6 \%$ agar, rather than the standard $0.35 \%$ agar. The ability of Sal. typhimurium to swarm was severely attenuated by flhE loss, and was restored by a plasmid expressing the flhE gene in trans from the pBAD18 arabinose-inducible promoter (Fig. 3). In contrast, a truncated version of FlhE lacking the putative $\mathrm{N}$-terminal 16 aa leader signal peptidase I sequence (MRKWLALLLFPLTVQA), and representing the mature form of the protein (aa 17-130), did not complement the swarming defect, even at high induction levels, indicating the importance of its secretion (Fig. 3). These data suggest that FlhE is a cell envelope protein that does have a role in flagellar-dependent motility, i.e. not cell swimming motility, but swarming migration.

\section{Loss of flhE does not impair flagellar gene expression or assembly}

To test if transcription of flagella genes is altered in the $\Delta f l h E$ mutant, plasmid-borne transcriptional lac $Z$ fusions were constructed to the flagellar class II promoter controlling the FlhD $\mathrm{C}_{2}$-dependent flhBAE operon, and to the flagellar class III $\left(\sigma^{28}\right.$-dependent $)$ fliC promoter. The activity of these promoter fusions during growth in liquid culture revealed that while transcription of the class II $f h B(A E)$ and class III fliC promoters was reduced 122- and 421-fold, respectively, in an flhDC mutant compared with the wild-type (Fig. 4a), transcription of both genes was unaltered in the $\Delta f l h E$ strain.

Loss of swarming motility could be due to attenuated posttranscriptional expression, or assembly of flagellar structural subunits. To examine this, levels of FliC protein were analysed by immunoblotting whole-cell, cytosolic, membrane-associated, extracellular and filament-incorporated fractions in the $\Delta f l h E$ strain, and compared with the wildtype (Fig. $4 \mathrm{~b}$ ). These assays showed that the intracellular level of FliC was unaltered, as was external flagellin in the filaments. The stability of the flagella to shearing in the $\Delta f l h E$ mutant was also unchanged (data not shown). It remained possible that the number or distribution of flagella on the cell surface was changed by the $\triangle$ flhE mutation, so we examined wild-type and $\Delta f l h E$ mutant cells harvested from swarm agar, and fixed to glass slides. Fig. 4(c) shows representative merged fluorescence microscopy images highlighting flagella (visualized using anti-flagellin primary antibody and FITC-labelled secondary antibody) and cell membranes (stained with SynaptoRed). The images indicate no obvious change in flagellar number (approximately 15 per cell) or distribution. The combined data establish that the $\Delta$ flhE mutation does not reduce flagella gene expression, assembly or stability, or differentiation into swarm cells. The attenuation of flagellar-dependent swarming must have a non-flagellar cause.

\section{Altered surface and biofilm properties of the $\Delta$ flhE strain}

Transposon mutations attenuating swarming motility of flagellated bacteria have been mapped to genes involved in the biosynthesis, not only of cell-free surfactants (Nakano et al., 1992; Eberl et al., 1999), but also of LPS (Toguchi et al., 2000; Belas et al., 1995) and EPS. Fig. 4(d) shows that representative samples of crude LPS from the wild-type and $\Delta f l h E$ strains, extracted according to Hitchcock \& Brown (1983), failed to highlight any obvious differences. Furthermore, low-molecular-mass (Fig. 4d) and high-molecular-mass LPS (data not shown) were analysed by silver staining (Guard-Petter et al., 1995), and, again, no changes between the two strains were evident. In common with LPS, some components of the EPS are thought to reduce surface resistance, and aid in swarming migration; for example, a mutation in the cmfA gene of the strongly swarming Proteus mirabilis abolished swarming migration due to loss of an EPS rich in galacturonic acid and galactosamine (Gygi et al., 1995). However, when crude acid hydrolysable EPS was assessed according to Gygi et al. (1995), again no differences were observed between the mutant and the wild-type (data not shown). This is unsurprising, since the biosynthetic pathways for LPS and several types of EPS are well characterized, and FlhE shares no motifs with their enzymes.

Such transposon mutations attenuating swarming motility commonly reduce the 'wettability' of the bacterial cell surface (Toguchi et al., 2000; Gygi et al., 1995; Belas et al., 1995; Lai et al., 2005), and swarming by such mutants, and of the weakly swarming Esc. coli K-12, can be recovered by the addition of external surfactants such as Tween 80 (Niu et al., 2005; Toguchi et al., 2000). The Sal. typhimurium $\Delta$ flhE strain was incubated on $0.6 \%$ agar plates containing the non-ionic detergent Tween 80 to increase wetting and reduce the surface tension of the agar. As shown in Fig. 5(a), swarming was recovered to almost the wild-type level. However, this could not be restored by addition of spent medium from a wild-type culture, indicating that the 
(a)

\begin{tabular}{cccc}
\hline & WT & $\Delta f l h E$ & $f l h D C^{-}$ \\
\hline$f l h B$ & 175 & 197 & 1.6 \\
fliC & 108 & 119 & 0.2 \\
\hline
\end{tabular}

(b)

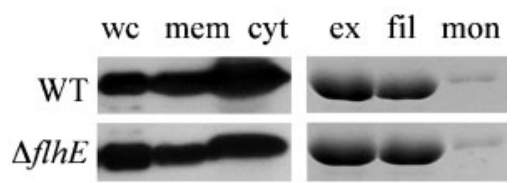

(c)

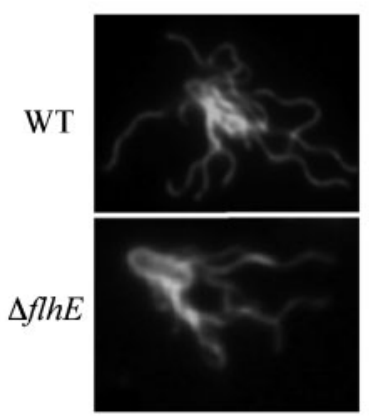

(d)

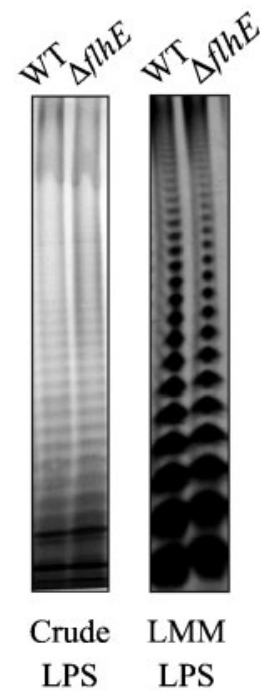

Fig. 4. Flagellar and LPS production in the wild-type and $\triangle f / h E$ mutant. (a) Activity $\left(10^{-2} \times\right.$ Miller units) of plasmid lac $Z$ gene fusions to the promoter regions of $f / h B$ (class II) and fliC (class III) in Sal. typhimurium wild-type (WT) and $\triangle \mathrm{flhE}$ and $\mathrm{f} / \mathrm{hDC} \mathrm{C}^{-}$ mutants. (b) Flagellin (FliC) in whole swarm cells (wc), and derived membrane (mem) and cytosolic (cyt) fractions. Total extracellular flagellin (ex) was separated into filament (fil) and soluble monomeric (mon), and analysed by SDS-PAGE and immunoblotting. (c) Swarm cells were stained using SynaptoRed and rabbit-anti-flagellin fluorescent antibodies, and viewed at 540 and $366 \mathrm{~nm}$, respectively, by fluorescence microscopy. (d) Crude and low-molecular-mass LPS (LMM) from wild-type and $\triangle f / h E$ strains was visualized by SDS-PAGE $(12 \%)$ and silver staining.

swarming defect of the $\Delta f l h E$ strain was not due to the absence of a secreted surfactant, such as serawettin from Ser. marcescens (Matsuyama et al., 1992). (a)

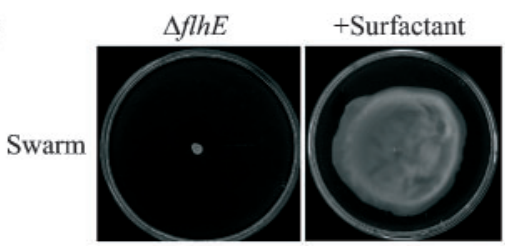

(b)

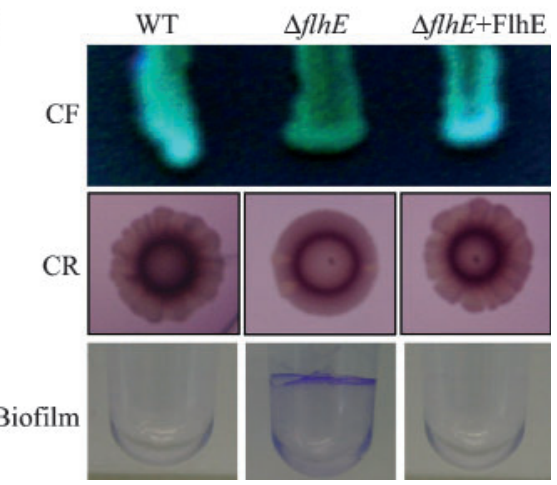

Fig. 5. Recovery of $\Delta f l h E$ swarming and changes in $\Delta f / h E$ mutant colony morphology. (a) The $\triangle f / h E$ mutant incubated $(14 \mathrm{~h})$ on swarm agar with and without Tween $80(0.02 \% \mathrm{w} / \mathrm{v})$ surfactant. (b) Wild-type (WT), the $\Delta f / h E$ mutant and the $\Delta f / h E$ mutant carrying pBAD18-FlhE were grown on agar containing calcoflour (CF; $200 \mu \mathrm{g} \mathrm{ml}^{-1}$ ) for $72 \mathrm{~h}$, agar containing Congo red $\left(40 \mu \mathrm{g} \mathrm{ml}^{-1}\right)$ and Coomassie blue $\left(20 \mu \mathrm{g} \mathrm{ml}^{-1}\right)$ (CR) for $96 \mathrm{~h}$, and in LB in PVC wells for $16 \mathrm{~h}$ before visualization of the biofilm with crystal violet (1\%).

It therefore seemed possible that other unknown FlhErelated surface properties were influencing the ability to swarm. We incubated the wild-type, the $\Delta f l h E$ mutant, and the $\Delta$ flhE mutant complemented with FlhE, on LB agar containing calcofluor, an LB agar containing Congo red and Coomassie blue, which have been used to highlight altered sugar composition (binding to $\beta$-glucans, particularly cellulose) and expression of thin aggregative filaments (curli) in the Sal. typhimurium extracellular matrix (Solano et al., 1998; Römling et al., 1998). Fig. 5(b) shows that the $\Delta f l h E$ mutant colonies have altered colony morphology on both media, and that this phenotype reverted to wild-type when FlhE was provided in trans. Such changes in calcofluor-binding properties of colonies have been shown to correlate with mutations in the $b c s$ operons responsible for biosynthesis of cellulose (Solano et al., 2002). This change is concomitant with defects in biofilm formation on a glass surface (Solano et al., 1998). However, the $\Delta f l h E$ mutant colonies were still able to make biofilm under similar conditions (i.e. glass in adherence test medium) (data not shown), suggesting that the $\Delta f l h E$ change in calcofluor binding was not due to alteration in cellulose production. Despite the Salmonella wild-type SJW1103 not displaying an rdar phenotype on Congo-red-containing medium, it did display a lacy edged colony morphology, while the $\Delta f h E$ colonies did not (Fig. 5b); this is another indicator of altered extracellular matrix composition. Altered colony 
morphology on Congo red plates can be associated with loss of thin aggregative filaments (tafi, also known as curli), encoded in Salmonella by the agf/csg operon (Römling et al., 1998; Solano et al., 2002; Guard-Petter, 2001). Nevertheless, there are examples in the literature of many variations in Congo red colony morphology, depending not only on curli expression, but also on expression of other factors, such as LPS and polysaccharide biosynthesis genes (e.g. $w z x E$ and wcaI) (Solano et al., 2002).

The extracellular matrices of Salmonella and Esc. coli are also involved in biofilm formation on other inert surfaces, such as PVC and polystyrene (Mireles et al., 2001; Römling et al., 1998), and reduced swarming and increased adherence to PVC have been reported in a $d d h C$ mutant (defective in $\mathrm{O}$ antigen synthesis) (Mireles et al., 2001). We assessed biofilm formation by wild-type and $\Delta$ flhE strains growing on the PVC surface of microtitre wells. After crystal violet staining (Fig. 5b), quantification according to Mireles et al. (2001) confirmed the visual impression that the $\Delta f l h E$ mutant formed approximately fivefold more biofilm than wild-type under all conditions tested (0.5-2\% glucose). Altered biofilm formation on PVC surfaces can also be associated with altered curli expression levels, but this is not the case for the $\Delta$ flhE strain, since assessment of curli levels using antiCsgA antisera indicated unchanged curli expression (data not shown). Nonetheless, the extracellular matrix is complex, and new components continue to come to light (Wang et al., 2004; Branda et al., 2005).

\section{Conclusion}

The data suggest that flhE belongs to the flagellar regulon, but is not required for individual cell motility, or any aspect of flagellar production. The data suggest that it nevertheless has a role in the swarming motility of peritrichously flagellated Gram-negative bacteria, possibly influencing the composition of the extracellular matrix, and increasing surface lubrication or wettability. The protein sequences deduced from the flhE genes cited in Fig. 1 are short sequences of $138-158$ aa that have no significant similarity with any protein in the current sequence databases. All FlhE proteins have a putative signal peptidase I leader sequence, indicative of a periplasmic or outer-membrane location, and removal of this N-terminal sequence (aa 1-16) apparently results in a loss of function. FlhE proteins have 7-13 proline residues, and proline-rich regions are often involved in protein-protein interactions (Seifert et al., 2004; Larsen et al., 1993). The flhE gene is not associated in the genome with other unknown genes, suggesting that it is not part of a pathway, but rather that it may encode a structural protein that acts alone on the surface, or contributes to a matrix-specific biofilm; for example, a protein that influences interaction with other cells in raft formation, or lubrication for surface movement. These possibilities are as yet unsupported by data, and it remains to be seen what this motility protein does.

\section{ACKNOWLEDGEMENTS}

We thank Jean Guard-Bouldin and Gillian Fraser for useful discussions, Johnathan Green and Lyndsey Brawn for assistance with fluorescence microscopy, and Ute Römling for anti-CsgA antisera. This work was supported by a Wellcome Trust Programme grant (C. H.).

\section{REFERENCES}

Allison, C. \& Hughes, C. (1991). Closely linked genetic loci required for swarm cell differentiation and multicellular migration by Proteus mirabilis. Mol Microbiol 5, 1975-1982.

Allison, C., Emody, L., Coleman, N. \& Hughes, C. (1994). The role of swarm cell differentiation and multicellular migration in the uropathogenicity of Proteus mirabilis. J Infect Dis 169, 1155-1158.

Altschul, S. F., Madden, T. L., Schäffer, A. A., Zhang, J., Zhang, Z., Miller, W. \& Lipman, D. J. (1997). Gapped BLAST and PSI-BLAST: a new generation of protein database search programs. Nucleic Acids Res 25, 3389-3402.

Auvray, F., Thomas, J., Fraser, G. M. \& Hughes, C. (2001). Flagellin polymerisation control by a cytosolic export chaperone. J Mol Biol 308, 221-229.

Belas, R., Goldman, M. \& Ashliman, K. (1995). Genetic analysis of Proteus mirabilis mutants defective in swarmer cell elongation. J Bacteriol 177, 823-828.

Branda, S. S., Vik, S. Friedman L. \& Kolter, R. (2005). Biofilms: the matrix revisited. Trends Microbiol 13, 20-26.

Chadsey, M. S., Karlinsey, J. E. \& Hughes, K. T. (1998). The flagellar anti-sigma factor FlgM actively dissociates Salmonella typhimurium sigma28 RNA polymerase holoenzyme. Genes Dev 12, 3123-3136.

Chaudhuri, R. R., Khan, A. M. \& Pallen, M. J. (2004). coliBASE: an online database for Escherichia coli, Shigella and Salmonella comparative genomics. Nucleic Acids Res 32, 296-299.

Datsenko, K. A. \& Wanner, B. L. (2000). One-step inactivation of chromosomal genes in Escherichia coli $\mathrm{K}-12$ using PCR products. Proc Natl Acad Sci U S A 97, 6640-6645.

Dufour, A., Furness, R. B. \& Hughes, C. (1998). Novel genes that upregulate the Proteus mirabilis flhDC master operon controlling flagellar biogenesis and swarming. Mol Microbiol 29, 741-751.

Eberl, L., Soren-Molin, I. \& Givskov, M. (1999). Surface motility of Serratia liquefaciens MG1. J Bacteriol 181, 1703-1712.

Fraser, G. M. \& Hughes, C. (1999). Swarming motility. Curr Opin Microbiol 2, 630-635.

Givskov, M., Eberl, L., Christiansen, G., Benedik, M. J. \& Molin, S. (1995). Induction of phospholipase and flagellar synthesis in Serratia liquefaciens is controlled by expression of the flagellar master operon flhD. Mol Microbiol 15, 445-454.

Guard-Petter, J. (2001). The chicken, the egg and Salmonella enteritidis. Environ Microbiol 3, 421-430.

Guard-Petter, J., Lakshmi, B., Carlson, R. \& Ingram, K. (1995). Characterization of lipopolysaccharide heterogeneity in Salmonella enteritidis by an improved gel electrophoresis method. Appl Environ Microbiol 61, 2845-2851.

Gygi, D., Rahman, M. M., Lai, H. C., Carlson, R., Guard-Petter, J. \& Hughes, C. (1995). A cell-surface polysaccharide that facilitates rapid population migration by differentiated swarm cells of Proteus mirabilis. Mol Microbiol 17, 1167-1175.

Hay, N. A., Tipper, D. J., Gygi, D. \& Hughes, C. (1997). A nonswarming mutant of Proteus mirabilis lacks the Lrp global transcriptional regulator. J Bacteriol 179, 4741-4746. 
Hay, N. A., Tipper, D. J., Gygi, D. \& Hughes, C. (1999). A novel membrane protein influencing cell shape and multicellular swarming of Proteus mirabilis. J Bacteriol 181, 2008-2016.

Hitchcock, P. J. \& Brown, T. M. (1983). Morphological heterogeneity among Salmonella lipopolysaccharide chemotypes in silver-stained polyacrylamide gels. J Bacteriol 154, 269-277.

Karlinsey, J. E., Tanaka, S., Bettenworth, V., Yamaguchi, S., Boos, W., Aizawa, S. I. \& Hughes, K. T. (2000). Completion of the hookbasal body complex of the Salmonella typhimurium flagellum is coupled to FlgM secretion and fliC transcription. Mol Microbiol 37, 1220-1231.

Kutsukake, K., Ohya, Y. \& lino, T. (1990). Transcriptional analysis of the flagellar regulon of Salmonella typhimurium. J Bacteriol 172, 741-747.

Lai, H. C., Soo, P. C., Wei, J. R., Yi, W. C., Liaw, S. J., Horng, Y. T., Lin, S. M., Ho, S. W., Swift, S. \& Williams, P. (2005). The RssAB twocomponent signal transduction system in Serratia marcescens regulates swarming motility and cell envelope architecture in response to exogenous saturated fatty acids. J Bacteriol 187, 3407-3414.

Larsen, R. A., Wood, G. E. \& Postle, K. (1993). The conserved proline-rich motif is not essential for energy transduction by Escherichia coli TonB protein. Mol Microbiol 10, 943-953.

Macnab, R. M. (1996). Escherichia coli and Salmonella typhimurium: Cellular and Molecular Biology, pp. 123-145. Edited by F. C. Neidhardt and others. Washington, DC: American Society for Microbiology.

Matsuyama, T., Kaneda, K., Nakagawa, Y., Isa, K., Hara-Hotta, H. \& Yano, I. (1992). A novel extracellular cyclic lipopeptide which promotes flagellum-dependent and -independent spreading growth of Serratia marcescens. J Bacteriol 174, 1769-1776.

McCarter, L. L. (2001). Polar flagellar motility of the Vibrionaceae. Microbiol Mol Biol Rev 65, 445-462.

Miller, J. H. (1972). Experiments in Molecular Genetics. Cold Spring Harbour, NY: Cold Spring Harbor Laboratory.

Minamino, T., lino, T. \& Kutuskake, K. (1994). Molecular characterization of the Salmonella typhimurium flhB operon and its protein products. $J$ Bacteriol 176, 7630-7637.

Mireles, J. R. II, Toguchi A. \& Harshey, R. M. (2001). Salmonella enterica serovar typhimurium swarming mutants with altered biofilm-forming abilities: surfactin inhibits biofilm formation. J Bacteriol 183, 5848-5854.

Nakano, M. M., Corbell, N., Besson, J. \& Zuber, P. (1992). Isolation and characterization of $s f p$ : a gene that functions in the production of the lipopeptide biosurfactant, surfactin, in Bacillus subtilis. Mol Gen Genet 232, 313-321.
Niu, C., Graves, J. D., Mokuolu, F. O., Gilbert, S. E. \& Gilbert, E. S. (2005). Enhanced swarming of bacteria on agar plates containing the surfactant Tween 80. J Microbiol Methods 62, 129-132.

Ohnishi, K., Ohto, Y., Aizawa, S., Macnab, R. M. \& lino, T. (1994). $\mathrm{FlgD}$ is a scaffolding protein needed for flagellar hook assembly in Salmonella typhimurium. J Bacteriol 176, 2272-2281.

Römling, U., Bian, Z., Hammar, M., Sierralta, W. D. \& Normark, S. (1998). Curli fibers are highly conserved between Salmonella typhimurium and Escherichia coli with respect to operon structure and regulation. J Bacteriol 180, 722-731.

Seifert, T. B., Bleiweis, A. S. \& Brady, L. J. (2004). Contribution of the alanine-rich region of Streptococcus mutans P1 to antigenicity, surface expression, and interaction with the proline-rich repeat domain. Infect Immun 72, 4699-4706.

Simons, R. W., Houman, F. \& Kleckner, N. (1987). Improved single and multicopy lac-based cloning vectors for protein and operon fusions. Gene 53, 85-96.

Solano, C., Sesma, B., Alvarez, M., Humphrey, T. J., Thorns, C. J. \& Gamazo, C. (1998). Discrimination of strains of Salmonella enteritidis with differing levels of virulence by an in vitro glass adherence test. J Clin Microbiol 36, 674-678.

Solano, C., Garcia, B., Valle, J., Berasain, C., Ghigo, J. M., Gamazo, C. \& Lasa, I. (2002). Genetic analysis of Salmonella enteritidis biofilm formation: critical role of cellulose. Mol Microbiol 43, 793-808.

Soutourina, O. A. \& Bertin, P. N. (2003). Regulation cascade of flagellar expression in Gram-negative bacteria. FEMS Microbiol Rev 27, 505-523.

Stafford, G. P., Ogi, T. \& Hughes, C. (2005). Binding and transcriptional activation of non-flagellar genes by the Escherichia coli flagellar master regulator FlhD2C2. Microbiology 151, 1779-1788.

Toguchi, A., Siano, M., Burkart, M. \& Harshey, R. M. (2000). Genetics of swarming motility in Salmonella enterica serovar typhimurium, critical role for lipopolysaccharide. J Bacteriol 182, 6308-6321.

Wang, Q., Frye, J. G., McClelland, M. \& Harshey, R. M. (2004). Gene expression patterns during swarming in Salmonella typhimurium, genes specific to surface growth and putative new motility and pathogenicity genes. Mol Microbiol 52, 169-187.

Wang, X., Preston, J. F., III \& Romeo, T. (2004). The pgaABCD locus of Escherichia coli promotes the synthesis of a polysaccharide adhesin required for biofilm formation. J Bacteriol 186, 2724-2734.

Yamaguchi, S., Fujita, H., Taira, T., Kutsukake, K., Homma, M. \& lino, T. (1984). Genetic analysis of three additional fla genes in Salmonella typhimurium. J Gen Microbiol 130, 3339-3342.

Edited by: S. C. Andrews 